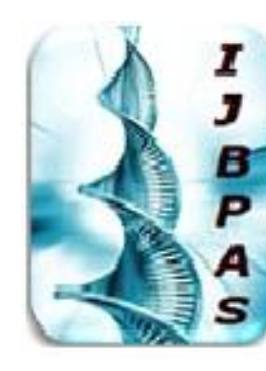

International Journal of Biology, Pharmacy and Allied Sciences (IJBPAS) 'A Bridge Between Caboratory and QRendo' WwW.iibpas.com

\title{
PERCEIVED EMOTIONAL INTELLIGENCE AMONG HEALTHCARE TEAM IN PAKISTAN: NEED OF THE HOUR
}

\author{
MALIK $M^{1 *}$, HAIDER $Z^{2}$ AND HUSSAIN $A^{3}$ \\ ${ }^{1}$ Vice President, Pakistan Society of Pharmacy Practice/Professor, Hamdard Institute of \\ Pharmaceutical Sciences, Hamdard University, Islamabad Campus \\ ${ }^{2}$ Hamdard Institute of Pharmaceutical Sciences, Hamdard University, Islamabad Campus \\ ${ }^{3}$ President, Pakistan Society of Pharmacy Practice/Professor/Dean, Faculty of Pharmacy, \\ Hamdard University, Islamabad Campus \\ *Corresponding Author: E Mail: madeehamalik15@gmail.com \\ Received 25 ${ }^{\text {th }}$ Aug. 2018; Revised 20 ${ }^{\text {th }}$ Sept. 2018; Accepted 24 ${ }^{\text {th }}$ Oct. 2018; Available online $1^{\text {st }}$ Feb. 2019 \\ https://doi.org/10.31032/IJBPAS/2019/8.2.4635
}

\begin{abstract}
Emotional intelligence plays an essential role in training of healthcare professionals as it has immense impact on establishing positive association among patients and them. The objective of this research was to measure emotional intelligence among different healthcare professionals including physicians, pharmacists and nurses and to determine its association with the demographic characteristics of the participants. A descriptive cross sectional study design was used. A pre-validated data collection tool designed by National Health Services (NHS) London Leadership Academy, was distributed to conveniently selected sample of 283 prescribers, 241 nurses and 215 pharmacists. After data collection, data was cleaned, coded and entered in SPSS version 21 and was statistically analyzed. Significant difference $(p \geq 0.05)$ in emotional intelligences was observed among different gender, age groups, profession, salary, experience, sector of practice and marital status. Females healthcare professionals were relatively more emotional intelligent. Married healthcare professionals and those having better salary status were relatively more emotionally intelligent. Pharmacists had better social skills than other healthcare professionals. This study provides a valuable insight into emotional intelligence and its
\end{abstract}


association with the demographic information of healthcare professionals. The results of the current study concluded that although healthcare professionals in Pakistan are emotionally intelligent but they still need to improve their emotion management, motivation, empathy and social skills. Pharmacists scored better in social skills and motivation than the other healthcare professionals

\section{Keywords: Emotional intelligence, physicians, pharmacists, nurses, Pakistan}

\section{INTRODUCTION}

Emotional intelligence is an important factor responsible for determining success in life and psychological well-being as well as developing interaction between individuals and their work environment [1]. Emotional intelligence assists to achieve the proficiency for professional and personal growth. People having emotional intelligence can easily face ecological change without any undesirable effect on their everyday life [2]. Being a good healthcare professionals also require to be empathetic in order to understand patients along with having scientific knowledge. Emotional intelligence plays an essential role in training of healthcare professionals as it has immense impact on establishing positive association among patients and them [3]. It helps to improve relationship between patients and healthcare professional in turn enhancing quality of care. A study reported that age has a significant impact on emotional intelligence. Senior physicians were found more emotionally intelligent than younger physicians [4]. On the other hand physicians working in private sector hospitals were reported with higher levels of emotional intelligence as compared to physicians working in public sector healthcare facilities in India [5]. Similarly, the nurses of private hospitals had better emotional intelligence than the nurses working in public sector hospitals. Experience also had an impact on emotional intelligence [6]. On the other hand, emotional intelligence was reported average among pharmacy students in Malaysia. They were found good in managing emotions but had average social skills [7]. Patients of the dentists with high general emotional intelligence scores were reported significantly more satisfied with treatment than patients of dentists with low emotional intelligence [8]. Limited studies have been found which assessed emotional intelligence among the healthcare team and not a single study to the best of our knowledge has been conducted in Pakistan till date. Therefore, the aim of this research was to enrich the relevant literature from Pakistan perspective 
and to highlight the need to develop relevant strategies nurturing the emotional intelligence of healthcare team to meet the challenges of rapidly evolving healthcare profession. The objective of this research was to measure emotional intelligence among different healthcare professionals including physicians, pharmacists and nurses and to determine its association with the demographic characteristics of the participants.

\section{METHODOLOGY}

A descriptive cross sectional study design was used to evaluate perceived emotional intelligence among healthcare professionals in Pakistan. Study approval was taken from the Ethical Committee of Hamdard University (ref no HU/ER 756). Beside this approval was also taken from respective authorities of different institutions and pharmaceutical industries from where data was collected. Moreover, consent was also taken from the respondents and their confidentiality of information was also assured. Physicians, nurses and pharmacists working in regulatory, academia, industry, hospitals, retail pharmacies, public and private health care facilities located in twin cities were included as study respondents. Rao Soft sample size calculator was used to determine the sample size. The calculated sample size was 382 for each group of respondents to achieve $95 \%$ confidence interval with $5 \%$ margin of error. The total sample came to be 1146. But due to unavailability of respondents at community pharmacies and unwillingness to participate, the total sample achieved for each group of healthcare professionals was: prescribers $(n=$ 283), nurse $(n=241)$ and pharmacists $(n=215)$. The response rate among the healthcare professionals was: prescribers (74.0\%), nurses $(63.0 \%)$ and pharmacists $(56.2 \%)$. Convenient sampling technique was used to select the respondents available at the time of data collection.

A pre-validated data collection tool designed by National Health Services (NHS) London Leadership Academy, was used to measure the emotional intelligence in this study. The questionnaire consisted of 50 items measuring different competencies of emotional intelligence including selfawareness, managing emotions, managing oneself, empathy, and social skill. Participants' responses were rated using a 5point Likert scale based on participants' reflection towards the item. The demographic components of the participants were added in the questionnaire. The questionnaires were self-administered by the principal investigator to the respondents. To avoid 
study biasness, questionnaires were collected back on the same day. After data collection, data was cleaned, coded and entered in SPSS version 21 and was statistically analyzed.

\section{RESULTS}

Out of 739 respondents, $40.9 \% \quad(n=302)$ were males while $59.1 \%(n=437)$ were females. Of the total respondents, physicians were $38.3 \%(n=283), 32.6 \%(n=241)$ were nurses and $29.1 \%(n=215)$ were pharmacists. Out of the total respondents, $45.5 \%(n=336)$ were working in public sector while $54.5 \%$ $(n=403)$ were working in private sector. Regarding the experience of respondents, $23.7 \%(n=175)$ had working experience of less than one year, $36.0 \%(n=266)$ had working experience of $1-5$ years, $23.3 \%(n=$ 172) had an experience of 6-10 years while $17.1 \%(n=126)$ had working experience of greater than 10 years (Table 1).

The mean score for different domains of emotional intelligence for physicians was self awareness (35.4, \pm 6.1 ), emotions (32.4, \pm $6.1)$, motivation $(33.3, \pm 5.8)$, empathy (34.1, $\pm 6.1)$ and social skills $(33.3, \pm 5.9)$. While for pharmacists emotional intelligence score was: self awareness (35.6, \pm 6.6 ), emotions (31.9, \pm 5.4$)$, motivation $(34.8, \pm 6.4$ ), empathy (34.1, \pm 5.5$)$ and social skills (35.1, \pm 6.5 ). Moreover for nurses the EI score was self awareness $(34.9, \pm 6.6)$, emotions (33.2, $\pm 6.0)$, motivation $(34.5, \pm 5.9)$, empathy $(34.0, \pm 6.1)$ and social skills $(34.7, \pm 6.5)$. A detail description is given in (Table 2).

Significant difference $(p \geq 0.05)$ in emotional intelligences was observed among different gender, age groups, profession, salary, experience, sector of practice and marital status. Females healthcare professionals were relatively more emotional intelligent. Married healthcare professionals and those having better salary status were relatively more emotionally intelligent. Pharmacists had better social skills than other healthcare professionals (Table 3 ). 
Table 1: Demographic Characteristics

\begin{tabular}{|c|c|c|}
\hline \multicolumn{2}{|c|}{ Indicators } & \multirow{2}{*}{$\begin{array}{c}\text { Total n (\%) } \\
378(51.2)\end{array}$} \\
\hline \multirow{4}{*}{ Age } & $20-30 \mathrm{Y}$ & \\
\hline & $31-40 \mathrm{Y}$ & $155(21.0)$ \\
\hline & $41-50 Y$ & $152(20.6)$ \\
\hline & $>50 \mathrm{Y}$ & $54(7.3)$ \\
\hline \multirow[b]{2}{*}{ Gender } & Male & $302(40.9)$ \\
\hline & Female & $437(59.1)$ \\
\hline \multirow[b]{2}{*}{ Marital Status } & Married & $424(57.4)$ \\
\hline & Unmarried & $315(42.6)$ \\
\hline \multirow{3}{*}{ Profession } & Physicians & $283(38.3)$ \\
\hline & Nurses & 241 (32.6) \\
\hline & Pharmacists & $215(29.1)$ \\
\hline \multirow[b]{2}{*}{ Sector of Practice } & Public & $335(45.3)$ \\
\hline & Private & $404(54.7)$ \\
\hline \multirow[b]{2}{*}{ Level of Experience } & $<1$ Year & $175(23.7)$ \\
\hline & 1-5 Years & $266(36.0)$ \\
\hline \multirow{6}{*}{ Current Salary } & 6-10 Years & $172(23.3)$ \\
\hline & $>10$ Years & $126(17.1)$ \\
\hline & Rs 10,000-20,000 & $113(15.3)$ \\
\hline & Rs 21,000-30,000 & $122(16.5)$ \\
\hline & Rs 31,000-50,000 & $175(23.7)$ \\
\hline & Rs $>\mathbf{5 0 , 0 0 0 0}$ & $329(44.5)$ \\
\hline
\end{tabular}


Table 2: Emotional Intelligence of Healthcare Professionals in Pakistan

\begin{tabular}{|c|c|c|c|c|c|c|c|c|c|c|c|c|}
\hline \multirow[t]{2}{*}{ Dimensions of EI } & \multicolumn{4}{|c|}{ Physicians } & \multicolumn{4}{|c|}{ Pharmacists } & \multicolumn{4}{|c|}{ Nurses } \\
\hline & Mean & Median & S.D & IQR & Mean & Median & S.D & IQR & Mean & S.D & Median & IQR \\
\hline Self Awareness & 35.4 & 6.1 & 36.0 & 9.0 & 35.6 & 6.6 & 36.0 & 11.0 & 34.9 & 6.6 & 35.0 & 9.0 \\
\hline Managing Emotions & 32.4 & 6.1 & 33.0 & 10.0 & 31.9 & 5.4 & 33.0 & 8.0 & 33.2 & 6.0 & 34.0 & 7.0 \\
\hline Motivating Oneself & 33.3 & 5.8 & 34.0 & 8.0 & 34.8 & 6.4 & 35.5 & 9.0 & 34.5 & 5.9 & 36.0 & 8.0 \\
\hline Empathy & 34.1 & 6.1 & 35.0 & 7.0 & 34.1 & 5.5 & 34.0 & 7.2 & 34.0 & 6.1 & 34.0 & 10.0 \\
\hline Social Skills & 33.3 & 5.9 & 34.0 & 9.0 & 35.1 & 6.5 & 34.0 & 9.0 & 34.7 & 6.5 & 36.0 & 7.0 \\
\hline
\end{tabular}

Table 3: Comparison of Mean Scores of Emotional intelligence according to different Demographic Mann-Whittney ${ }^{\mathrm{a}}$ Kruskal-Wallis test ${ }^{\mathrm{b}}$ Test $(p \geq 0.05)$

\begin{tabular}{|c|c|c|c|c|c|c|c|c|c|c|c|c|c|c|c|c|c|c|c|c|c|}
\hline \multicolumn{2}{|c|}{ Demographics } & \multicolumn{5}{|c|}{ Self Awareness } & \multicolumn{3}{|c|}{$\begin{array}{l}\text { Managing } \\
\text { Emotions }\end{array}$} & \multicolumn{4}{|c|}{$\begin{array}{c}\text { Motivating } \\
\text { Oneself }\end{array}$} & \multicolumn{4}{|c|}{ Empathy } & \multicolumn{4}{|c|}{ Social skill } \\
\hline & & $\mathbf{n}$ & $\begin{array}{c}\text { Mean } \\
\text { rank }\end{array}$ & $\begin{array}{c}\text { Test } \\
\text { Stats. }\end{array}$ & $\begin{array}{c}P \\
\text { value }\end{array}$ & $\mathbf{n}$ & $\begin{array}{c}\text { Mean } \\
\text { rank }\end{array}$ & $\begin{array}{c}\text { Test } \\
\text { Stats. }\end{array}$ & $\begin{array}{c}P \\
\text { value }\end{array}$ & $\mathbf{n}$ & $\begin{array}{c}\text { Mean } \\
\text { rank }\end{array}$ & $\begin{array}{c}\text { Test } \\
\text { Stats. }\end{array}$ & $\begin{array}{c}P \\
\text { value }\end{array}$ & $\mathbf{n}$ & $\begin{array}{c}\text { Mean } \\
\text { rank }\end{array}$ & $\begin{array}{c}\text { Test } \\
\text { Stats. }\end{array}$ & $\begin{array}{c}P \\
\text { value }\end{array}$ & $\mathbf{n}$ & $\begin{array}{c}\text { Mean } \\
\text { rank }\end{array}$ & $\begin{array}{c}\text { Test } \\
\text { Stats. }\end{array}$ & $\begin{array}{c}\mathbf{P} \\
\text { value }\end{array}$ \\
\hline \multirow{2}{*}{ Gender } & M & 302 & 324.83 & 52323.5 & 0.001 & 302 & 362.40 & 63691.0 & 0.425 & 302 & 347.45 & 59176.5 & 0.016 & 302 & 349.47 & 59785.0 & 0.029 & 302 & 355.26 & $61535.5^{a}$ & 0.133 \\
\hline & $\mathbf{F}$ & 437 & 400.27 & & & 437 & 375.25 & & & 437 & 385.58 & & & 437 & 384.19 & & & 437 & 379.36 & & \\
\hline \multirow{2}{*}{$\begin{array}{c}\text { Marital } \\
\text { Status }\end{array}$} & M & 424 & 349.79 & 58212.0 & 0.006 & 424 & 383.53 & 60194.5 & 0.029 & 424 & 376.50 & 63174.0 & 0.263 & 424 & 365.68 & 64947.0 & 0.617 & 424 & 373.28 & $64118.0^{a}$ & 0.473 \\
\hline & U.M & 313 & 393.92 & & & 313 & 349.31 & & & 313 & 358.83 & & & 313 & 373.50 & & & 313 & 362.01 & & \\
\hline \multirow{3}{*}{ Profession } & Phy. & 283 & 372.76 & $1.229^{b}$ & 0.539 & 283 & 365.37 & $4.801^{b}$ & 0.089 & 283 & 339.17 & $9.615^{b}$ & 0.009 & 283 & 375.15 & $0.369^{b}$ & 0.832 & 283 & 334.80 & $12.464^{b}$ & 0.002 \\
\hline & Nur. & 241 & 357.5 & & & 241 & 393.06 & & & 241 & 387.68 & & & 241 & 363.80 & & & 241 & 356.04 & & \\
\hline & Phar. & 215 & 378.68 & & & 215 & 350.25 & & & 215 & 390.75 & & & 215 & 370.17 & & & 215 & 385.55 & & \\
\hline \multirow{4}{*}{$\begin{array}{l}\text { Age of } \\
\text { Respond- } \\
\text { ents }\end{array}$} & $\begin{array}{l}20- \\
30 y\end{array}$ & 378 & 407.04 & $24.847^{b}$ & 0.001 & 378 & 357.04 & $5.796^{b}$ & 0.122 & 378 & 368.22 & $0.793^{b}$ & 0.853 & 378 & 381.14 & $4.145^{b}$ & 0.244 & 378 & 376.68 & $3.983^{b}$ & 0.270 \\
\hline & $\begin{array}{l}31- \\
40 \mathrm{y}\end{array}$ & 155 & 331.84 & & & 155 & 362.71 & & & 155 & 376.00 & & & 155 & 370.78 & & & 155 & 349.67 & & \\
\hline & $\begin{array}{l}41- \\
50 y\end{array}$ & 152 & 337.39 & & & 152 & 394.17 & & & 152 & 375.82 & & & 152 & 358.30 & & & 152 & 384.37 & & \\
\hline & $>50 y$ & 54 & 305.93 & & & 54 & 413.62 & & & 54 & 348.87 & & & 54 & 322.76 & & & 54 & 334.40 & & \\
\hline \multirow{4}{*}{$\begin{array}{l}\text { Level of } \\
\text { Experien- } \\
\text { ce }\end{array}$} & $<1 y$ & 175 & 412.65 & $14.682^{b}$ & 0.002 & 175 & 365.16 & $5.541^{b}$ & 0.137 & 175 & 372.41 & $23.393^{b}$ & 0.001 & 175 & 392.19 & $7.476^{b}$ & 0.058 & 175 & 377.36 & $11.089^{b}$ & 0.12 \\
\hline & $1-5 y$ & 266 & 368.85 & & & 266 & 351.16 & & & 266 & 349.81 & & & 266 & 363.40 & & & 266 & 352.13 & & \\
\hline & $6-10 y$ & 172 & 325.11 & & & 172 & 380.00 & & & 172 & 340.33 & & & 172 & 339.26 & & & 172 & 349.90 & & \\
\hline & $>10 y$ & 126 & 371.54 & & & 126 & 402.85 & & & 126 & 449.78 & & & 126 & 395.09 & & & 126 & 421.08 & & \\
\hline
\end{tabular}

\footnotetext{
IJBPAS, February, 2019, 8(2)
} 


\begin{tabular}{|c|c|c|c|c|c|c|c|c|c|c|c|c|c|c|c|c|c|c|c|c|c|}
\hline \multirow{4}{*}{$\begin{array}{l}\text { Current } \\
\text { Salary }\end{array}$} & $\begin{array}{l}10 \mathrm{k}- \\
20 \mathrm{k}\end{array}$ & 113 & 329.34 & $15.367^{b}$ & 0.001 & 113 & 380.46 & $21.479^{b}$ & 0.001 & 113 & 328.22 & $14.760^{b}$ & 0.002 & 113 & 351.78 & $12.934^{b}$ & 0.005 & 113 & 326.26 & $16.568^{b}$ & 0.001 \\
\hline & $\begin{array}{l}21 \mathrm{k}- \\
30 \mathrm{k}\end{array}$ & 122 & 320.64 & & & 122 & 295.55 & & & 122 & 326.63 & & & 122 & 313.41 & & & 122 & 324.38 & & \\
\hline & $\begin{array}{l}31 \mathrm{k}- \\
50 \mathrm{k}\end{array}$ & 175 & 394.05 & & & 175 & 360.99 & & & 175 & 402.82 & & & 175 & 387.61 & & & 175 & 407.14 & & \\
\hline & $>50 \mathrm{k}$ & 329 & 388.43 & & & 329 & 398.81 & & & 329 & 382.98 & & & 329 & 387.88 & & & 329 & 381.17 & & \\
\hline \multirow{2}{*}{ Sector } & Pub. & 335 & 398.04 & 57606.0 & 0.001 & 335 & 407.31 & 54835.5 & 0.001 & 335 & 403.95 & 55961.0 & 0.001 & 335 & 393.24 & 59551.0 & $0.005 a$ & 335 & 391.14 & $59919.5^{\mathrm{a}}$ & 0.01 \\
\hline & Pri. & 404 & 344.80 & & & 404 & 338.07 & & & 404 & 340.86 & & & 404 & 349.77 & & & 404 & 350.55 & & \\
\hline
\end{tabular}




\section{DISCUSSION}

Emotional intelligence in healthcare settings is an important element of the competencies of the health professionals and quality of the service provided in the health organization. Health professionals are dealing with people who are under severe emotional stress and may or may not be able to communicate these emotions. The level of emotional intelligence may vary among different professionals according to their responsibility in the organization and the significance they give to the application of emotional intelligence in performing their tasks. [3]. The results of the present study showed that the healthcare professionals in twin cities of Pakistan had good self awareness but they need to improve their emotion management, motivation, empathy and social skills. However, pharmacists possessed relatively better social skills with higher motivation levels than the other healthcare professionals. Moreover, female healthcare professionals had relatively more self awareness. Similarly, self awareness score was found higher among female healthcare professionals in Malaysia [2].

Self motivated individuals constantly work toward their goals [9].The results of the present study showed that female healthcare professionals were comparatively more motivated than males. Female healthcare professionals also scored more in empathy than males, thus, female healthcare professionals were relatively more emotionally intelligence than males. Similar results were reported in a study which showed females were believed to had higher emotional intelligence due to social or biological factors [10].

Personal, family and professional factors influence emotional intelligence. The results of the present study showed that senior healthcare professionals were relatively more emotionally intelligent than younger professionals. Similar findings were reported from another study conducted in United states of America [11]. Furthermore, the results of present study indicated that emotional intelligence was found comparatively more among highly paid healthcare professionals. This argument is supported by a study conducted in United States [12]. On the other hand, the current study revealed that healthcare professionals working in public healthcare facilities had better self awareness, emotional management, motivation, empathy and social skills than those working in private hospitals. Healthcare professionals working in public healthcare facilities were found more emotionally intelligent than those working in 
private sector. In contrary to these findings, a study conducted in India reported physicians working in private sector more emotionally intelligent than those working in public sector hospitals [5].

\section{CONCLUSION}

This study provides a valuable insight into emotional intelligence and its association with the demographic information of healthcare professionals. The results of the current study concluded that although healthcare professionals in Pakistan are emotionally intelligent but they still need to improve their emotion management, motivation, empathy and social skills. Pharmacists scored better in social skills and motivation than the other healthcare professionals. Clinical outcomes and issues such as malpractice liability may be affected by healthcare professional's ability to convey emotional awareness and empathy to patients. Thus, effective strategies must be designed to improve emotional intelligence among healthcare professionals which can lead to better health outcomes, as patients may become more apt to medication adherence.

\section{REFERENCES}

[1] Kh, N., et al., The effect of teaching emotional intelligence (EI) items on job related stress in physicians and nurses working in ICU wards in hospitals, Yerevan, Armenia. Int J Collaborat Res on Internal Medicine Public Health, 2011. 3: p. 704-13.

[2] Hassali, M.A.A., et al., Perceived Emotional Intelligence and Its Association with the Demographic Characteristics among Pharmacy Students: A Cross-Sectional Study. Journal of Pharmacy Practice and Community Medicine, 2017. 3(3).

[3] Burkiewicz, A., Structure of emotional intelligence among first year students of selected directions of medicine. Procedia-Social and Behavioral Sciences, 2015. 190: p. 129-134.

[4] Khanam, N., et al., A study on various dimensions of emotional intelligence among doctors. International Journal Of Community Medicine And Public Health, 2017. 5(1): p. 390-394.

[5] Tomar, R., A Study of Emotional Intelligence among Doctors. International Journal of Innovative Research and Development, 2016. 5(6).

[6] Tomar, R., A study of emotional intelligence among nurses. Int J Sci Res Edu, 2016. 4(4): p. 5204-11. 
[7] Mohamed Azmi Ahmad Hassali, et al., Perceived Emotional Intelligence and Its Association with the Demographic Characteristics among Pharmacy Students: A CrossSectional Study. Journal of Pharmacy Practice and Community Medicine, 2017. 3(3): p. 108-113.

[8] Anushka, G. and L. Nagesh, Empathy and Emotional Intelligence in Dental Practitioners of Bareilly City-A Cross sectional Study. National Journal of Integrated Research in Medicine, 2018. 7(4): p. 106-112.

[9] Batool, B.F., Emotional intelligence and effective leadership. Journal of Business Studies Quarterly, 2013. 4(3): p. 84.
[10] Bhaskaran Unnikrishnan, et al., Association of emotional intelligence with academic performance among medical students in South India. Asian J Pharm Clin Res, 2015. 8(2): p. 300302.

[11] Shipley, N.L., M.J. Jackson, and S. Segrest, The effects of emotional intelligence, age, work experience, and academic performance. 2010.

[12] Rode, J.C., et al., A time-lagged study of emotional intelligence and salary. Journal of Vocational Behavior, 2017. 101: p. 77-89. 